\title{
Comparison of musculoskeletal disorder health claims between construction floor layers and a general working population
}

\author{
Ann Marie Dale, ${ }^{1}$ Daniel Ryan, ${ }^{2}$ Laura Welch, ${ }^{3}$ Margaret A Olsen, ${ }^{4}$ Bryan Buchholz, ${ }^{5}$ \\ Bradley Evanoff ${ }^{1}$
}

${ }^{1}$ Division of General Medical Sciences Department,

Washington University School of Medicine in St. Louis, Saint Louis, Missouri, USA

${ }^{2}$ Department of Medical Social Sciences, Northwestern University, Feinberg School of Medicine, Chicago, Illinois, USA

${ }^{3}$ The Center for Construction Research and Training CPWR, Silver Spring, Maryland, USA

${ }^{4}$ Divisions of Infectious Diseases and Public Health Sciences, Washington University School of Medicine in St. Louis, Saint Louis, Missouri, USA

${ }^{5}$ Work Environment Department, University of Massachusetts Lowell, Lowell, Massachusetts, USA

\section{Correspondence to} Dr Ann Marie Dale, Division of General Medical Sciences, Washington University School of Medicine, $660 \mathrm{~S}$. Euclid Avenue Campus Box 8005, Saint Louis, MO 63110, USA: adale@dom.wustl.edu

Received 6 May 2014 Revised 27 August 2014 Accepted 1 September 2014 Published Online First 15 September 2014

\section{ABSTRACT \\ Objectives Compare rates of medical insurance claims for musculoskeletal disorders (MSD) between workers in a construction trade and a general worker population to determine if higher physical exposures in construction lead to higher rates of claims on personal medical insurance.}

Methods Health insurance claims between 2006 and 2010 from floor layers were frequency matched by age, gender, eligibility time and geographic location to claims from insured workers in general industry obtained from MarketScan. We extracted MSD claims and dates of service from six regions of the body: neck, low back, knee, lower extremity, shoulder and distal arm, and evaluated differences in claim rates.

Results Fifty-one per cent of floor layers ( $n=1475$ ) experienced musculoskeletal claims compared with 39\% of MarketScan members $(p<0.001)$. Claim rates were higher for floor layers across all body regions with nearly double the rate ratios for the knee and neck regions (RR 2.10 and 2.07). The excess risk was greatest for the neck and low back regions; younger workers had disproportionately higher rates in the knee, neck, low back and distal arm. A larger proportion of floor layers (22\%) filed MSD claims in more than one body region compared with general workers $(10 \% ; p<0.001)$.

Conclusions Floor layers have markedly higher rates of MSD claims compared with a general worker population, suggesting a shifting of medical costs for work-related MSD to personal health insurance. The occurrence of disorders in multiple body regions and among the youngest workers highlights the need for improved work methods and tools for construction workers.

\section{INTRODUCTION}

Musculoskeletal disorders (MSDs) are a leading work-related health issue among construction workers, ${ }^{1}$ but determining the true burden of morbidity associated with work activities is difficult within current surveillance and medical insurance systems. In the USA, work-related injuries are covered by employers' workers' compensation (WC) insurance plans, while non-work conditions are covered under personal insurance plans, which may be provided by an employer, a union or the government. There is growing evidence that workrelated injuries and illnesses are under-reported due to employer and employee factors ${ }^{2-4}$; studies have shown the cost-shifting of work-related claims to

\section{What this paper adds}

- Musculoskeletal disorders are common among construction floor layers, yet several studies suggest that there is a shift of work-related health claims from workers' compensation insurance to personal health insurance.

- Shifting of claims to personal health insurance places the burden of disease on workers and their families and shifts attention to managing disease rather than prevention efforts of work-related causes.

- In this study, construction floor layers showed rates of personal health claims for chronic musculoskeletal disorders that were nearly double the rates for a general population of workers.

- Under-recognition of occupational diseases created by policies and regulations delays efforts towards prevention and limits resources for reducing the high physical demands of a job.

private or public health insurance programmes. ${ }^{5} 6$ Some construction workers have resorted to using the emergency room to receive medical treatment for work-related events that are never filed under WC insurance. ${ }^{78}$ This is in part due to the lack of training by emergency room and family practice physicians to recognise work-related risk and causal attribution to work. ${ }^{7}$ Shifting of claims from workrelated coverage to other sources places the burden of disease on workers and their families and shifts attention to managing the disease rather than focusing prevention efforts on work-related causes.

The WC system is best suited to handling claims for acute injury; in most WC systems, it is more difficult to establish work-relatedness and claim coverage for medical treatment of chronic MSDs. Chronic MSDs develop slowly over months to years before the disorder is evident and a diagnosis is confirmed. ${ }^{9}{ }^{10}$ Claims for MSDs may be denied by the WC system in some states if work-related events or activities are not the 'prevailing factor' in causing the injury, or if the cause cannot be ascribed solely to the current employer. ${ }^{11}$ In addition to the difficulty of getting WC coverage, there 
are other disincentives for filing WC by workers including fear of termination, jeopardising rewards from zero injury programmes, and fear of increasing WC costs for the company. ${ }^{12}$ Many construction workers change employers frequently or work as independent contractors ${ }^{13}$ so intermittent coverage or lack of WC coverage may preclude reporting. Workers with these conditions often seek medical care through personal health coverage systems rather than through WC. ${ }^{14-16}$

Many construction workers are not eligible for personal health coverage. When insurance coverage was examined by occupation, construction workers had the second lowest rate of health insurance, second only to agricultural workers; only $68 \%$ had coverage. ${ }^{17}$ Coverage levels were much higher among union workers $(81 \%)$ compared with their non-union counterparts (34\%). ${ }^{17}$ Construction trade union members are eligible for health coverage through joint labour-management trust funds, obtained through the collective bargaining agreement process, if they meet the required number of work hours. This insurance is portable across employers that contribute to the fund. Without such a fund that allows a worker to carry insurance from one employer to another, the short-term employment characteristic of the industry discourages employers from providing coverage.

Under-reporting of work-related claims and shifting of claims from the WC system to the private health system will obscure an association between WC claims and physical work exposures. ${ }^{13} 1819$ This study not only described the distributions and compared rates of personal (not WC) health insurance claims for MSDs, but also compared rates seen between union floor layers (FL) and workers in general industry. We hypothesised that the injury rates of MSDs would be higher among construction FL than among workers from a general working population after adjusting for age, gender and time eligible to file claims.

\section{MATERIALS AND METHODS}

\section{Data sources}

FL health claims data

We obtained health claims data of covered FL union members from the Carpenters Health and Welfare Trust Fund (CHWTF) in Missouri. The Fund manages the health coverage, pension and disability benefits for active union workers (carpenters, FL and other union groups in the local area) and their dependants. Health coverage eligibility requires active union membership status and an initial accrual of 500 work hours in a 6-month period, with an additional accrual of 300 work hours per quarter or $1200 \mathrm{~h}$ per year for ongoing eligibility. Members who do not meet the required number of work hours in a given period are given the option to obtain temporary group health coverage through self-pay or COBRA (Consolidated Omnibus Budget Reconciliation Act) options. We restricted the health claims data set to actively working union members who had a minimum age of 18 years, logged at least $80 \%$ of their total work hours with a floor laying contractor, and were covered under the union's health insurance plan and thus eligible to file a claim between January 2006 and December 2010. We selected only the period of continuous eligibility for each FL member obtained through either active work hours or temporary group health coverage for the final analytic sample. The sample was restricted to male workers since fewer than $1 \%$ were female.

General population health claims data

The general population data set came from the Truven Health Analytics MarketScan Commercial Claims and Encounters Database, a data warehouse of individual-level healthcare claims from large employers and health plans. ${ }^{20}$ The MarketScan (MS) database is the largest collection of employer-based health records in the USA, with data on over 88 million unique workers from 2006 to 2010 . The database provides longitudinal tracking of persons through employer-sponsored health plans and captures care from hospital, outpatient and pharmacy records.

We restricted the data to active working males with a minimum age of 18 years at the start of their enrolment period, employed within the 12 states of the North Central geographic region of the USA, and enrolled in a fee-for-service health plan. In order to create a final sample with the same age and eligibility profile as the FL data set, we stratified the actively working (full time or part time), primary insured adult males in the 12 states into strata based on 1-year periods of eligibility, and then sampled within the five strata to frequency match the distribution of age within categories $(18-24,25-34,35-44,45-54$ and $55+$ years) to the FL population. This process resulted in a randomly selected age-matched and eligibility-matched sample from the general population data, with a 10:1 ratio of workers in general industry to FL in the final data set. From the FL and sampled MS data set, we extracted claims for inpatient and outpatient services and primary or secondary International Classification of Diseases, 9th Revision, Clinical Modification (ICD-9-CM) diagnosis codes. This study was approved by the Institutional Review Board of Washington University School of Medicine.

\section{ICD-9 codes and body region categories}

We extracted ICD-9-CM diagnosis codes for MSDs and the dates of service from claim records. The ICD-9-CM list of diagnoses of interest was compiled from codes used in several previous studies ${ }^{21-27}$ including 354.XX (carpal tunnel syndrome and other nerves); 715.XX (osteoarthrosis); 717.XX (knee meniscus); 718.87 and 719.47 (ankle pain); 721.XX, 722.XX, 723. XX, 724.XX (cervical, thoracic and lumbar problems); 726.XX, 727.XX, 728.XX (injuries to the shoulder, elbow, wrist, hand, digits, knee and ankle); 739.XX (back pain); 836.XX (knee); and 840.XX, 841.XX, 842.XX，844.XX，846.XX，847.XX (sprain and strain). To reduce the number of categories in our analysis, we combined ICD-9-CM codes by the primary body region and created six categories: neck, shoulder/upper arm, distal arm (includes elbow to fingers), low back, knee, and other lower extremity (including hip, ankle and foot). Diagnosis codes that did not specify a body region were excluded.

\section{Data analysis}

We created the two data sets as described above. To determine the rate of MSD claims, we counted the number of participants who filed at least one ICD-9 code for each body part and censored the time at risk on the date of the first claim in the period. We computed the annual rates for each year and overall rate for the entire period of 2006-2010. We computed the proportion of insured workers with one or more MSD claims per body part as well as the incident rates calculated as the number of participants with MSD claims by the total months each participant was eligible to file a claim. Participants with an MSD were considered eligible until their first MSD claim date; those without MSD claims were considered eligible for their total contribution time. We compared the incident rates based on 10 person-years of eligibility of the FL and MS groups, testing for statistical difference between populations using a z-test ratio of independent proportions. The claims for each population were stratified by age to determine if MSDs disproportionately affected particular age groups. We explored whether workers 
Table 1 Distribution of age and eligibility among the floor layer sample $(n=1475)$

\begin{tabular}{lrc}
\hline & N & Per cent \\
\hline Age (years) & 316 & \\
$18-24$ & 475 & 21.4 \\
$25-34$ & 379 & 32.2 \\
$35-44$ & 233 & 25.7 \\
$45-54$ & 72 & 15.8 \\
$55+$ & 227 & 4.9 \\
Eligible health insurance coverage (months) & \\
$1-12$ & 172 & 15.4 \\
$13-24$ & 181 & 11.7 \\
$25-36$ & 176 & 12.3 \\
$37-48$ & 719 & 11.9 \\
$49-60$ & & 48.7 \\
\hline
\end{tabular}

filed claims for more than one body region including the low back, neck and knee during the period and whether the number of workers with claims differed between the work groups. SAS Software V.9.1 $1^{28}$ was used for all analyses.

\section{RESULTS}

There were 1475 male FL and 14750 male MS members in the respective data sets, frequency matched by 1 -year categories of health insurance enrolment and age category. Table 1 shows the age distribution of FL at the beginning of the study period and during the duration of continuous eligibility. The final cohorts were nearly identical for age (FL: mean 35.2 years (SD 10.9); MS mean 35.1 years (SD 10.7); $\mathrm{p}=0.77$ ) and similar for insurance eligibility distribution (FL: mean 40.7 months (SD 20.5); MS: mean 41.3 months (SD 19.9); $\mathrm{p}=0.28$ ). A larger proportion of the FL experienced MSD diagnoses for one or more body parts (51.2\%) compared with the MS group $38.5 \%$; $\mathrm{Z}=9.47, \mathrm{p}<0.001)$.

The proportion of workers with at least one claim for an MSD during the study was significantly higher among the FL compared with the MS group as shown in table 2. The incident claim rates, calculated as the number of participants with MSD claims over their eligibility time at risk, showed that the rates were higher for each body region among the FL compared with the MS group. The rate ratios were more than double for the FL in the knee and neck regions compared with the MS group.

Stratifying the data by age group, the rate ratios in table 3 show that FL had consistently higher rates of MSD claims than the MS cohort across many age categories for most body parts. In general, the largest rate ratios were found in the youngest group (18-24 years) of FL for the knee, neck, low back and distal arm regions, with decreasing ratios relative to MS workers in the middle-age groups but not in the oldest age group. The risk differences were largest for the low back and neck regions.

Claims for multiple body regions were more common among the FL. Table 4 shows the proportion of workers with claims for more than one body region including the low back, neck and knee. A significantly larger proportion of the FL (22.4\%) had claims filed for more than one of these three body regions compared with the MS cohort of workers $(9.6 \%$; z-test $\mathrm{p}<0.001)$.

\section{DISCUSSION}

Our study showed that the rates of individuals with one or more health insurance claims for chronic MSDs among FL were nearly double the rates for a general population of male workers in the Midwest. Although the rates among FL were higher for all body regions, the largest proportional differences were for claims of the knee and neck, and these claims were proportionally higher among the youngest FL relative to the same age group of workers in general industry. The large differences in MSD claims for this active working group of FL, and the fact that these differences were largest among young workers, suggest that workers are using their personal health insurance for treatment of work-related conditions. These data point to two main concerns: that FL have more chronic MSDs than the workforce in general, and that payment for medical care related to work activities is being shifted onto the worker's personal health insurance rather than being paid by the employer through the WC system.

Most previous studies that report on FL have demonstrated high rates for knee disorders ${ }^{29}$ including knee osteoarthritis, meniscal tears and knee bursitis. ${ }^{21}{ }^{30-33}$ Studies using selfreported symptoms among construction workers have shown greater physical symptoms in many body regions when compared with foremen and non-construction workers, ${ }^{34}$ but there has been little investigation of medical diagnoses in regions of the body other than the knee among FL, ${ }^{35}$ or of the occurrence of

Table 2 Proportion of individuals and incidence of claims per 10 person-years of eligibility stratified by body part between 2006 and 2010

\begin{tabular}{|c|c|c|c|c|c|c|c|c|c|}
\hline & \multicolumn{3}{|c|}{$\mathrm{FL}(n=1475)$} & \multicolumn{3}{|c|}{ MS $(n=14750)$} & \multirow[b]{2}{*}{$\begin{array}{l}\text { p } \\
\text { Value* }\end{array}$} & \multirow[b]{2}{*}{$\begin{array}{l}\text { Rate ratio (95\% Cl; FL/ } \\
\text { MS) }\end{array}$} & \multirow[b]{2}{*}{$\begin{array}{l}\text { Risk } \\
\text { difference }\end{array}$} \\
\hline & n (\%) & $\begin{array}{l}\text { Eligible } \\
\text { months }\end{array}$ & $\begin{array}{l}\text { Incidence }(95 \% \\
\mathrm{Cl})\end{array}$ & n (\%) & $\begin{array}{l}\text { Eligible } \\
\text { months }\end{array}$ & $\begin{array}{l}\text { Incidence }(95 \% \\
\mathrm{Cl})\end{array}$ & & & \\
\hline Knee & $164(11.1)$ & 55630 & $0.35(0.30$ to 0.41$)$ & $843(5.7)$ & 600760 & 0.17 (0.16 to 0.18$)$ & $<0.001$ & 2.10 (1.78 to 2.48$)$ & 0.18 \\
\hline Neck & $346(23.5)$ & 50057 & $0.83(0.74$ to 0.92$)$ & 1908 (12.9) & 570015 & $0.40(0.38$ to 0.42$)$ & $<0.001$ & 2.07 (1.84 to 2.32$)$ & 0.43 \\
\hline Low back & $545(36.9)$ & 43551 & 1.50 (1.38 to 1.63$)$ & $3410(23.1)$ & 525390 & $0.78(0.75$ to 0.80$)$ & $<0.001$ & 1.93 (1.76 to 2.11$)$ & 0.72 \\
\hline $\begin{array}{l}\text { Distal } \\
\text { arm }\end{array}$ & $135(9.2)$ & 56636 & $0.29(0.24$ to 0.33$)$ & $906(6.1)$ & 598784 & $0.18(0.17$ to 0.19$)$ & $<0.001$ & $1.58(1.32$ to 1.89$)$ & 0.11 \\
\hline Shoulder & $122(8.3)$ & 57004 & $0.26(0.21$ to 0.30$)$ & $852(5.8)$ & 600593 & $0.17(0.16$ to 0.18$)$ & $<0.001$ & 1.51 (1.25 to 1.82$)$ & 0.09 \\
\hline Other LE & $117(7.9)$ & 56978 & $0.25(0.20$ to 0.29$)$ & $1064(7.2)$ & 595747 & $0.21(0.20$ to 0.23$)$ & 0.311 & $1.15(0.95$ to 1.39$)$ & 0.04 \\
\hline $\begin{array}{l}\text { Any } \\
\text { claim }\end{array}$ & 755 (51.2) & 36169 & 2.50 (2.33 to 2.68$)$ & $5684(38.5)$ & 450805 & 1.51 (1.47 to 1.55$)$ & $<0.001$ & 1.66 (1.53 to 1.79$)$ & 0.99 \\
\hline
\end{tabular}


Table 3 Incidence of claims per 10 person-years of eligibility by body part and age group over the period between 2006 and 2010

\begin{tabular}{|c|c|c|c|c|c|c|c|c|}
\hline & \multicolumn{3}{|c|}{ FL $(n=1475)$} & \multicolumn{3}{|c|}{ MS (n=14 750) } & \multirow[b]{2}{*}{$\begin{array}{l}\text { Rate ratio } \\
\text { (95\% Cl; FL/MS) }\end{array}$} & \multirow[b]{2}{*}{ Risk difference } \\
\hline & n (\%) & Eligible months & $\begin{array}{l}\text { Incidence } \\
(95 \% \mathrm{Cl})\end{array}$ & n (\%) & Eligible months & $\begin{array}{l}\text { Incidence } \\
(95 \% \mathrm{Cl})\end{array}$ & & \\
\hline \multicolumn{9}{|l|}{ Knee } \\
\hline $18-24$ & $21(6.6)$ & 9224 & $0.27(0.16$ to 0.39$)$ & $98(3.1)$ & 127456 & 0.09 (0.07 to 0.11$)$ & $2.96(1.85 \text { to } 4.74)^{*}$ & 0.18 \\
\hline $25-34$ & $45(9.5)$ & 17123 & $0.32(0.22$ to 0.41$)$ & $224(4.7)$ & 194272 & 0.14 (0.12 to 0.16$)$ & $2.28(1.65 \text { to } 3.14)^{*}$ & 0.18 \\
\hline $35-44$ & $46(12.1)$ & 16013 & $0.34(0.25$ to 0.44$)$ & $228(6.0)$ & 156098 & $0.18(0.15$ to 0.20$)$ & $1.97(1.43 \text { to } 2.70)^{*}$ & 0.16 \\
\hline $45-54$ & $42(18.0)$ & 10065 & $0.50(0.35$ to 0.65$)$ & $217(9.3)$ & 94339 & 0.28 (0.24 to 0.31$)$ & $1.81(1.30 \text { to } 2.52)^{*}$ & 0.22 \\
\hline $55+$ & $10(13.9)$ & 3205 & $0.37(0.14$ to 0.61$)$ & 76 (10.6) & 28595 & 0.32 (0.25 to 0.39$)$ & $1.17(0.61$ to 2.27$)$ & 0.05 \\
\hline \multicolumn{9}{|l|}{ Neck } \\
\hline $18-24$ & $48(15.2)$ & 8578 & $0.67(0.48$ to 0.86$)$ & $265(8.4)$ & 123134 & $0.26(0.23$ to 0.29$)$ & $2.60(1.91 \text { to } 3.54)^{*}$ & 0.41 \\
\hline $25-34$ & $116(24.0)$ & 15431 & $0.90(0.74$ to 1.07$)$ & $632(13.3)$ & 182157 & $0.42(0.38$ to 0.45$)$ & $2.17(1.78 \text { to } 2.64)^{*}$ & 0.48 \\
\hline $35-44$ & $104(27.4)$ & 13905 & $0.90(0.73$ to 1.07$)$ & $563(14.9)$ & 146158 & $0.46(0.42$ to 0.50$)$ & $1.94(1.58 \text { to } 2.39)^{*}$ & 0.44 \\
\hline $45-54$ & $59(25.3)$ & 9245 & 0.77 (0.57 to 0.96$)$ & $354(15.2)$ & 90522 & 0.47 (0.42 to 0.52$)$ & $1.63(1.24 \text { to } 2.15)^{*}$ & 0.30 \\
\hline $55+$ & $19(26.4)$ & 2898 & 0.79 (0.43 to 1.14$)$ & $94(13.1)$ & 28044 & $0.40(0.32$ to 0.48$)$ & $1.97(1.19 \text { to } 3.20)^{*}$ & 0.39 \\
\hline \multicolumn{9}{|l|}{ Low back } \\
\hline $18-24$ & $78(24.7)$ & 7652 & $1.22(0.95$ to 1.49$)$ & $530(16.8)$ & 115762 & 0.55 (0.50 to 0.60$)$ & $2.23(1.76 \text { to } 2.83)^{*}$ & 0.67 \\
\hline $25-34$ & $175(36.8)$ & 13722 & $1.53(1.30$ to 1.76$)$ & 1039 (21.9) & 170258 & 0.73 (0.69 to 0.78$)$ & $2.09(1.78 \text { to } 2.45)^{*}$ & 0.80 \\
\hline $35-44$ & $155(40.9)$ & 12015 & 1.55 (1.30 to 1.79$)$ & $997(26.3)$ & 132873 & 0.90 (0.84 to 0.96$)$ & $1.72(1.45 \text { to } 2.04)^{*}$ & 0.65 \\
\hline $45-54$ & $98(42.1)$ & 8044 & $1.46(1.17$ to 1.75$)$ & $657(28.2)$ & 81604 & 0.97 (0.89 to 1.04$)$ & $1.51(1.22 \text { to } 1.87)^{*}$ & 0.49 \\
\hline $55+$ & $39(54.2)$ & 2118 & 2.21 (1.52 to 2.90$)$ & $187(26.0)$ & 24893 & $0.90(0.77$ to 1.03$)$ & $2.45(1.74 \text { to } 3.46)^{*}$ & 1.31 \\
\hline \multicolumn{9}{|l|}{ Distal arm } \\
\hline $18-24$ & $16(5.1)$ & 9326 & $0.21(0.10$ to 0.31$)$ & $102(3.2)$ & 127268 & 0.10 (0.08 to 0.11$)$ & $2.14(1.26 \text { to } 3.63)^{*}$ & 0.11 \\
\hline $25-34$ & $39(8.2)$ & 17462 & $0.27(0.18$ to 0.35$)$ & $246(5.2)$ & 193359 & 0.15 (0.13 to 0.17$)$ & $1.76(1.25 \text { to } 2.46)^{*}$ & 0.12 \\
\hline $35-44$ & $41(10.8)$ & 16111 & $0.31(0.21$ to 0.40$)$ & $285(7.5)$ & 154330 & $0.22(0.20$ to 0.25$)$ & $1.38(0.99$ to 1.91$)$ & 0.09 \\
\hline $45-54$ & $31(13.3)$ & 10421 & $0.36(0.23$ to 0.48$)$ & $215(9.2)$ & 94790 & 0.27 (0.24 to 0.31$)$ & $1.31(0.90$ to 1.91$)$ & 0.09 \\
\hline $55+$ & $8(11.1)$ & 3316 & $0.29(0.09$ to 0.49$)$ & $58(8.1)$ & 29037 & 0.24 (0.18 to 0.30$)$ & $1.21(0.58$ to 2.53$)$ & 0.05 \\
\hline \multicolumn{9}{|l|}{ Shoulder } \\
\hline $18-24$ & $5(1.6)$ & 9601 & $0.06(0.01$ to 0.12$)$ & $121(3.8)$ & 127254 & 0.11 (0.09 to 0.13$)$ & 0.55 (0.22 to 1.34$)$ & -0.05 \\
\hline $25-34$ & $39(8.2)$ & 17540 & $0.27(0.18$ to 0.35$)$ & $223(4.7)$ & 194015 & 0.14 (0.12 to 0.16$)$ & $1.93(1.38 \text { to } 2.72)^{*}$ & 0.13 \\
\hline $35-44$ & $39(10.3)$ & 16323 & 0.29 (0.20 to 0.38$)$ & $243(6.4)$ & 155364 & 0.19 (0.16 to 0.21$)$ & $1.53(1.09 \text { to } 2.14)^{*}$ & 0.10 \\
\hline $45-54$ & $28(12.0)$ & 10304 & $0.33(0.21$ to 0.45$)$ & $205(8.8)$ & 94787 & $0.26(0.22$ to 0.30$)$ & $1.26(0.85$ to 1.86$)$ & 0.07 \\
\hline $55+$ & $11(15.3)$ & 3236 & $0.41(0.17$ to 0.65$)$ & $60(8.3)$ & 29173 & 0.25 (0.18 to 0.31$)$ & 1.65 (0.87 to 3.14$)$ & 0.16 \\
\hline \multicolumn{9}{|l|}{ Other LE } \\
\hline $18-24$ & $12(3.8)$ & 9343 & 0.15 (0.07 to 0.24$)$ & $146(4.6)$ & 126335 & $0.14(0.12$ to 0.16$)$ & $1.11(0.62$ to 2.00$)$ & 0.01 \\
\hline $25-34$ & $25(5.3)$ & 17731 & $0.17(0.10$ to 0.24$)$ & $312(6.6)$ & 192475 & 0.19 (0.17 to 0.22$)$ & $0.87(0.58$ to 1.31$)$ & -0.02 \\
\hline $35-44$ & $45(11.9)$ & 16052 & $0.34(0.24$ to 0.43$)$ & $308(8.1)$ & 153891 & 0.24 (0.21 to 0.27$)$ & $1.40(1.02 \text { to } 1.92)^{*}$ & 0.10 \\
\hline $45-54$ & $23(9.9)$ & 10586 & $0.26(0.15$ to 0.37$)$ & $229(9.8)$ & 94146 & 0.29 (0.25 to 0.33$)$ & 0.89 (0.58 to 1.37 ) & -0.03 \\
\hline $55+$ & $12(16.7)$ & 3266 & 0.44 (0.19 to 0.69$)$ & $69(9.6)$ & 28900 & $0.29(0.22$ to 0.35$)$ & 1.54 (0.83 to 2.84$)$ & 0.15 \\
\hline \multicolumn{9}{|c|}{ Multiple MSDs } \\
\hline $18-24$ & $62(19.6)$ & 8393 & $0.89(0.67$ to 1.11$)$ & $293(9.3)$ & 123730 & 0.28 (0.25 to 0.32$)$ & $3.12(2.37 \text { to } 4.10)^{*}$ & 0.61 \\
\hline $25-34$ & $133(28.0)$ & 15031 & $1.06(0.88$ to 1.24$)$ & $682(14.4)$ & 183317 & $0.45(0.41$ to 0.48$)$ & $2.38(1.98 \text { to } 2.86)^{*}$ & 0.61 \\
\hline $35-44$ & $135(35.6)$ & 13510 & $1.20(1.00$ to 1.40$)$ & $693(18.3)$ & 144367 & 0.58 (0.53 to 0.62$)$ & $2.08(1.73 \text { to } 2.50)^{*}$ & 0.62 \\
\hline $45-54$ & $82(35.2)$ & 8773 & 1.12 (0.88 to 1.36$)$ & $514(22.1)$ & 87459 & 0.71 (0.64 to 0.77 ) & $1.59(1.26 \text { to } 2.01)^{*}$ & 0.41 \\
\hline $55+$ & $29(40.3)$ & 2667 & $1.30(0.83$ to 1.78$)$ & $131(18.2)$ & 27172 & 0.58 (0.48 to 0.68$)$ & $2.26(1.51 \text { to } 3.37)^{*}$ & 0.72 \\
\hline
\end{tabular}

Incidence=number of individuals with claims per 10 person-years of eligibility during the period; rate ratio: incidence of FL/incidence of MS people; risk difference: the difference between the incidence of FL to the incidence of MS people.

${ }^{*}$ Indicates rate ratios with significant difference between the FL rate and MS cohort rate since the lower bound is above 1.0

FL, floor layers; LE, lower extremity; MS, MarketScan; MSDs, musculoskeletal disorders.

diagnoses in multiple body regions. The current study showed that FL saw a physician and received musculoskeletal diagnoses across many body regions; FL suffer from high rates of low back, neck, shoulder and distal arm disorders in addition to knee conditions. Importantly, almost one-quarter of FL received medical treatment for disorders in more than one body region within the relatively short period of time of this 5 -year investigation.

All construction work including laying floors is physically demanding. Past literature highlights the occupational physical risks of work tasks among FL and supports a causative relationship between work activities and health claims of the knee. ${ }^{36-40} \mathrm{~A}$ few recent studies on FL have found high workrelated physical exposures for other body parts including the low back, neck and upper extremities 354142 in addition to the knee. The all-fours position (kneeling with the hands on the floor) is commonly used in laying floors since most of the work is performed at the floor level. Workers use forceful and repetitive motions of the arms and hands to spread adhesive, lay ceramic tiles and nail boards while kneeling on the floor. This combination of exposures occurring for long periods of time 
Table 4 Proportion of members with claims for one or more body regions of the low back neck and/or knee between work groups during the period 2006-2010

\begin{tabular}{|c|c|c|c|}
\hline & $\begin{array}{l}\text { Floor layers }(n=1475) \\
n(\%)\end{array}$ & $\begin{array}{l}\text { MarketScan }(n=14750) \\
n(\%)\end{array}$ & p Value* \\
\hline Nonet & 801 (54.3) & $10142(68.8)$ & $<0.001$ \\
\hline Low back & $217(14.7)$ & 2043 (13.9) & 0.363 \\
\hline Neck & $61(4.1)$ & $681(4.6)$ & 0.399 \\
\hline Knee & $65(4.4)$ & 465 (3.2) & 0.001 \\
\hline Multipleł & 331 (22.4) & $1419(9.6)$ & $<0.001$ \\
\hline
\end{tabular}

during the working day may increase the risk of injury to multiple body regions, as was found in the current study. The National Institute for Occupational Safety and Health (NIOSH) has published recommendations to prevent or reduce knee disorders among carpet layers, ${ }^{43}$ including knee pads and use of a power kicker. In addition to these recommendations for knee protection, NIOSH has other recommendations to prevent back, shoulder and other MSDs among construction workers. ${ }^{44}$ Our findings support the need for continued attention to the prevention of overexertion injuries, given the high prevalence of potentially work-related MSDs seen in medical claims data.

Another key finding of this study was the comparatively large MSD morbidity seen among the youngest floor laying work group. Even though young workers possess good physical strength and flexibility, they experience MSDs when their work tasks exceed their physical capabilities. The high physical demands in many construction jobs have been reported to lead to greater functional limitations and early disability among construction workers. ${ }^{45-48}$ Arndt et al ${ }^{49}$ showed that German construction workers were more than twice as likely to become disabled due to musculoskeletal disease compared with the general workforce. High rates of MSD-related disability and early departure from the productive workforce highlight the need for interventions to be applied to all level of workers within the construction industry.

Even though this study was conducted in the USA and therefore influenced by the policy and regulations of the two-part insurance system, the concern for cost-shifting from the employer to the employee and their families is not limited to the USA. Under-recognition of occupational diseases can occur in many kinds of health systems, shifting responsibility for occupational injury and disease to the worker. $\mathrm{LaDou}^{50}$ reports that underrecognition of occupational diseases is common to all European Union countries, with a transfer of resources to the employer's benefit, with much of the cost burden being shared between injured workers and general health budgets through social security coverage of diseases, disability and unemployment. In addition, use of personal or social health systems rather than ones created to compensate occupational injury delays efforts and limits resources for reducing the high physical demands of the job.

The primary limitation in this study was the comparison of claims derived from separate insurance programmes. Age and eligibility in a health plan may affect an individual's ability to file a health plan claim for chronic MSDs, so we selected data from the MS database by frequency matching on age group, gender, geographical location and duration of health insurance eligibility, to allow for the most valid comparisons between medical claims.
Since we used an existing working population, we were unable to account for a healthy worker effect; given that FL had higher physical demands than the general working population, it is more likely that the former would have differentially left employment due to symptoms or MSDs; if this were the case, it would result in an underestimate of the rate of MSDs. While it is possible that some of the observed differences could be related to differential utilisation of health services, differences in insurance administration or assignment of diagnostic codes by providers, we believe it is unlikely that the size of the differences in MSD rates between the FL and the general worker population represented in MS was only due to differences in insurance plans. We also did not account for other potential differences between the work groups including education and income, although past literature has shown few associations with MSDs except with the lowest income and education group. ${ }^{51}$

The strength of this study was the availability of health claims for a large group of FL that spanned the full working age. We were able to frequency match on important demographic characteristics of a general population of workers and describe differences in proportions of individuals with claims for musculoskeletal injuries. This study provided the opportunity to explore musculoskeletal claims from all regions of the body for these two work groups, and demonstrated important differences in claim rates for medical treatment of MSDs.

\section{CONCLUSIONS}

Construction FL seek treatment for potentially work-related conditions through their personal health programme as shown by the excessively high rate ratios of claims for MSDs when compared with general working populations. Shifting claims to personal health records shifts the costs from the employer to the worker and lessens attention towards developing better work practices and improved tools and equipment. The observation that the youngest workers are seeking medical treatment, often for MSDs in multiple body regions, indicates that these workers are at increased risk of disabling MSDs starting early in their careers. There is an urgent need for developing better work methods for FL and other construction workers.

Acknowledgements The authors would like to thank the Carpenter's Health and Welfare Trust Fund for providing the data used in this study and Harini Subramaniam for conducting data analysis on the MarketScan data.

Contributors All coauthors participated in the planning of the research, the interpretation of the data analysis, and reviewed and edited the final manuscript. Data analysis was conducted by DR (floor layers data) and Harini Subramaniam (MarketScan data).

Funding This study was supported by research funding from CPWR-The Center for Construction Research and Training (NIOSH U60 OH009762). Services provided by the Center for Administrative Data Research for managing the MarketScan data files were supported in part by the Washington University Institute of Clinical and Translational Sciences grant UL1 TR000448 from the National Center for Advancing Translational Sciences (NCATS) of the National Institutes of Health (NIH), Grant Number R24 HS19455 through the Agency for Healthcare Research and Quality (AHRQ), and Grant Number KM1CA156708 through the National Cancer Institute $(\mathrm{NCl})$ at the National Institutes of Health $(\mathrm{NIH})$ and from the National Center for Research Resources (NCRR), a component of the National Institutes of Health (NIH).

\section{Competing interests None.}

Ethics approval This study was approved by the Institutional Review Board of Washington University School of Medicine, and St. Louis Missouri USA.

Provenance and peer review Not commissioned; externally peer reviewed.

\section{REFERENCES}

1 Turner JA, Franklin G, Turk DC. Predictors of chronic disability in injured workers: a systematic literature synthesis. Am J Ind Med 2000;38:707-22. 
2 Pransky G, Snyder T, Dembe A, et al. Under-reporting of work-related disorders in the workplace: a case study and review of the literature. Ergonomics 1999;42:171-82.

3 Utterback DF, Schnorr TM. eds. Use of workers' compensation data for occupational injury \& illness prevention. Worker's Compensation Data Use Workshop; 2009; Washington, DC: National Institute for Occupational Safety and Health, 2010.

4 Fan ZJ, Bonauto DK, Foley MP, et al. Underreporting of work-related injury or illness to workers' compensation: individual and industry factors. J Occup Environ Med 2006;48:914-22.

5 Glazner JE, Borgerding J, Lowery JT, et al. Construction injury rates may exceed national estimates: evidence from the construction of Denver International Airport. Am J Ind Med 1998;34:105-12.

6 Lipscomb HJ, Dement JM, Silverstein B, et al. Who is paying the bills? Health care costs for musculoskeletal back disorders, Washington State Union Carpenters, 1989-2003. J Occup Environ Med 2009;51:1185-92.

7 Schoenfisch AL, Lipscomb HJ, Marshall SW, et al. Declining rates of work-related overexertion back injuries among union drywall installers in Washington State, 1989-2008: improved work safety or shifting of care?. Am J Ind Med 2014;57:184-94.

8 Zwerling C, Miller ER, Lynch CF, et al. Injuries among construction workers in rural lowa: emergency department surveillance. J Occup Environ Med 1996;38:698-704.

9 Evanoff BA, Dale AM, Descatha A. A conceptual model of musculoskeletal disorders for occupational health practitioners. Int I Occup Med Environ Health 2014:27:145-48.

10 Gardner BT, Dale AM, Descatha A, et al. Natural history of upper extremity musculoskeletal symptoms and resulting work limitations over 3 years in a newly hired working population. J Occup Environ Med 2014;56:588-94.

11 Boden L, Spieler E. The relationship between workplace injuries and workers' compensation claims: the importance of system design. In: Victor R, Carrubba L, eds. Workers' compensation: where have we come from? Where are we going? Cambridge, Massachusetts: Workers' Compensation Research Institute, 2010.

12 Azaroff LS, Levenstein C, Wegman DH. Occupational injury and illness surveillance: conceptual filters explain underreporting. Am J Public Health 2002;92:1421-9.

13 Probst TM, Brubaker TL, Barsotti A. Organizational injury rate underreporting: the moderating effect of organizational safety climate. J Appl Psychol 2008;93:1147-54.

14 Morse TF, Dillon C, Warren N, et al. The economic and social consequences of work-related musculoskeletal disorders: the Connecticut Upper-Extremity Surveillance Project (CUSP). Int J Occup Environ Health 1998:4:209-16.

15 Leigh JP, Marcin JP. Workers' compensation benefits and shifting costs for occupational injury and illness. J Occup Environ Med 2012;54:445-50.

16 Morse T, Dillon C, Kenta-Bibi E, et al. Trends in work-related musculoskeletal disorder reports by year, type, and industrial sector: a capture-recapture analysis. Am J Ind Med 2005;48:40-9.

17 The Center for Construction Research and Training. The construction chart book: The U.S. construction industry and its workers. 5th edn. Silver Spring, MD: The Center for Construction Research and Training, 2013.

18 Welch LS, Dong $X$, Carre F, et al. Is the apparent decrease in injury and illness rates in construction the result of changes in reporting? Int J Occup Environ Health 2007:13:39-45.

19 Glazner J, Borgerding J, Lowery J, et al. Construction injury rates may exceed national estimates: evidence from the construction of Denver International Airport. Am J Ind Med 1998:34:105-12.

20 Hansen L, Chang S. Health research data for the real world: the MarketScan databases. White Paper. Ann Arbor, Michigan: Truven Health Analytics, Inc., 2012.

21 Yuan L, Buchholz B, Dale AM. Knee disorders among carpenters in the St. Louis area. Open Occup Health Saf J 2011;3(Suppl 1-M4):31-8.

22 Lipscomb HJ, Cameron W, Silverstein B. Incident and recurrent back injuries among union carpenters. Occup Environ Med 2008:65:827-34.

23 Lipscomb HJ, Cameron W, Silverstein B. Back injuries among union carpenters in Washington State, 1989-2003. Am J Ind Med 2008;51:463-74.

24 Park RM, Nelson NA, Silverstein MA, et al. Use of medical insurance claims for surveillance of occupational disease: an analysis of cumulative trauma in the auto industry. J Occup Environ Med 1992;34:731-7.
25 Sluiter JK, Rest KM, Frings-Dresen MH. Criteria document for evaluating the work-relatedness of upper-extremity musculoskeletal disorders. Scand J Work Environ Health 2001;27(Suppl 1):1-102.

26 Cherkin DC, Deyo RA, Volinn E, et al. Use of the International Classification of Diseases (ICD-9-CM) to identify hospitalizations for mechanical low back problems in administrative databases. Spine (Phila Pa 1976) 1992:17:817-25.

27 Washington State Department of Labor and Industries. Musculoskeletal disorders. [cited 7 January 2014]. http://www.Ini.wa.gov/Safety/Research/OccHealth/MuscDis/ default.asp

28 SAS. Version 9.1 ed. Cary, NC: SAS Institute Inc., 2006.

29 Andersen S, Thygesen LC, Davidsen M, et al. Cumulative years in occupation and the risk of hip or knee osteoarthritis in men and women: a register-based follow-up study. Occup Environ Med 2012;69:325-30.

30 Coggon D, Croft P, Kellingray S, et al. Occupational physical activities and osteoarthritis of the knee. Arthritis Rheum 2000;43:1443-9.

31 Kivimäki J, Riihimäki H, Hänninen K. Knee disorders in carpet and floor layers and painters. Scand J Work Environ Health 1992;18:310-16.

32 Village J, Morrison JB, Leyland A. Biomechanical comparison of carpet-stretching devices. Ergonomics 1993;36:899-909.

33 Hartmann B, Fleischer AG. Physical load exposure at construction sites. Scand J Work Environ Health 2005;31(Suppl 2):88-95.

34 Holmström E, Engholm G. Musculoskeletal disorders in relation to age and occupation in Swedish construction workers. Am J Ind Med 2003;44:377-84

35 Jensen L, Kofoed L. Musculoskeletal disorders among floor layers: is prevention possible? App/ Occup Environ Hyg 2002;17:797-806

36 Jensen LK. Knee-straining work activities, self-reported knee disorders and radiographically determined knee osteoarthritis. Scand J Work Environ Health 2005;31(Suppl 2):68-74.

37 Jensen LK, Mikkelsen S, Loft IP, et al. Work-related knee disorders in floor layers and carpenters. J Occup Environ Med 2000;42:835-42.

38 Rytter S, Egund N, Jensen LK, et al. Occupational kneeling and radiographic tibiofemoral and patellofemoral osteoarthritis. J Occup Med Toxicol 2009:4:19.

39 Rytter $\mathrm{S}$, Jensen LK, Bonde JP, et al. Occupational kneeling and meniscal tears: a magnetic resonance imaging study in floor layers. J Rheumatol 2009;36:1512-9.

40 Rytter $S$, Jensen LK, Bonde JP. Clinical knee findings in floor layers with focus on meniscal status. BMC Musculoskelet Disord 2008;9:144

41 McGaha J, Miller K, Descatha A, et al. Exploring physical exposures and identifying high-risk work tasks within the floor layer trade. Appl Ergon 2014;45:857-64.

42 Ditchen D, Ellegast R, Rehme G. GonKatast: A Measure of Land to Professional Knee Loads. Alte Heerstr 111, 53757 Sankt Augustin. 2010.

43 NIOSH. Preventing knee injuries and disorders in carpet layers. DHHS (NIOSH) Publication No. 1990-104. 1990. http://www.cdc.gov/niosh/docs/90-104/

44 Albers JT, Estill CF; National Institute for Occupational Safety and Health (NIOSH). Simple solutions: ergonomics for construction workers. Cincinnati, OH: U.S. Department of Health and Human Services, Public Health Service, Centers for Disease Control and Prevention, NIOSH, DHHS, 2007.

45 Welch LS, Haile E, Boden LI, et al. Impact of musculoskeletal and medical conditions on disability retirement-a longitudinal study among construction roofers. Am J Ind Med 2010;53:552-60.

46 Welch L, Haile E, Boden LI, et al. Musculoskeletal disorders among construction roofers - physical function and disability. Scand J Work Environ Health 2009:35:56-63.

47 Turner JA, Franklin G, Fulton-Kehoe D, et al. Early predictors of chronic work disability associated with carpal tunnel syndrome: a longitudinal workers' compensation cohort study. Am J Ind Med 2007:50:489-500.

48 LeMasters $G$, Bhattacharya A, Borton $E$, et al. Functional impairment and quality of life in retired workers of the construction trades. Exp Aging Res 2006;32:227-42.

49 Arndt V, Rothenbacher D, Daniel U, et al. Construction work and risk of occupational disability: a ten year follow up of 14,474 male workers. Occup Environ Med 2005;62:559-66.

50 Ladou J. The European influence on workers' compensation reform in the United States. Environ Health. 2011;10:103.

51 Kortt M, Baldry J. The association between musculoskeletal disorders and obesity. Aust Health Rev 2002;25:239-46. 